\title{
INTRODUCTION
}

\section{Working beneath the surface: interplay of biomechanics, physiology and behavioural ecology in diving seabirds}

\author{
Rory P. Wilson ${ }^{1, *}$, Yutaka Watanuki ${ }^{2}$, Nobuyuki Miyazaki ${ }^{3}$, Brent S. Stewart ${ }^{4}$ \\ ${ }^{1}$ Institute of Environmental Sustainability, Pure and Applied Ecology, School of the Environment and Society, \\ Swansea University, Swansea SA2 8PP, UK \\ ${ }^{2}$ Graduate School of Fisheries Sciences, Hokkaido University, 3-1-1 Minato-cho, Hokodate, Hokkaido 040-0821, Japan \\ ${ }^{3}$ Ocean Research Institute, The University of Tokyo, 1-15-1 Minamidai, Nanakano, Tokyo 164-8639, Japan \\ ${ }^{4}$ Hubbs-SeaWorld Research Institute, 2595 Ingraham Street, San Diego, California 92109, USA
}

\begin{abstract}
This Theme Section looks at new approaches in the study of seabird foraging ecology, with particular emphasis on the use of recently developed recording devices attached to birds. It includes studies with energy as a theme, such as the energetics of foraging in Magellanic penguins, how dive efficiency varies with depth in emperor penguin, optimality of stroke frequency in diving seabirds, and how using energy to counteract depth-dependent buoyancy may limit pursuit speeds in hunting imperial shags. A more physiological approach is adopted in two studies, one on the dive capacity of emperor penguins and one on planktivorous auklets. Foraging ecology is examined more broadly in a study on the foraging behaviour of breeding thick-billed murres while a modelling approach is used to describe foraging profitability in aucklets (the smallest marine endotherms) feeding on pelagic patches. Finally, consideration is given to bird-attached instrument artefacts in path reconstruction of diving birds using dead-reckoning.
\end{abstract}

KEY WORDS: Diving seabirds $\cdot$ Biomechanics $\cdot$ Energy efficiency $\cdot$ Foraging ecology $\cdot$ Recording devices

Many seabirds dive - some to more than $100 \mathrm{~m}$ - to exploit prey in places where they cannot access oxygen (Kooyman 1989, Boyd 1997) while being subject to the severe physical constraints of buoyancy, drag (Wilson et al. 1992, Lovvorn 2001), temperature (Butler \& Jones 1997) and pressure (Kooyman 1989). Physiological adaptations for the parsimonious use of oxygen during submergence have been explored extensively by way of laboratory experiments. Recently developed silicon chip technology now enables us to study physiological and behavioural mechanisms used by freeliving, diving seabirds.
The Pacific Seabird Group is dedicated to studying all aspects of Pacific seabirds. The group's most recent conference during February 2009 in Hakodate, Japan, attended by 180 people from 11 different countries, included a symposium on the foraging behaviour and movements of free-living seabirds underwater, with emphasis on data obtained using recording devices attached to birds. This Theme Section considers how data derived from such devices can help us understand seabird foraging ecology through specific case studies, including a keynote presentation (Wilson et al. 2010), five papers presented at the symposium and four 
related papers. The first paper looks at power use during the descent and ascent phases of dives made by Magellanic penguins Spheniscus magellanicus, where buoyancy is the primary modulator of energy expenditure (Wilson et al. 2010). The second, by Lovvorn et al. (2010), notes that although the size of the smallest marine endotherms, the auklets, currently makes them unsuitable for an animal-attached device approach, judicious modelling can help make predictions about the way these animals must operate in their cold, marine environment. Small, planktivorous alcids are also the subject of the work by Elliott et al. (2010), which examines how oxygen storage capacity relates to foraging behaviour in two sympatric species, while, in stark contrast, Ponganis et al. (2010) focus on how oxygen store depletion and the aerobic dive limit relate to dive performance in the world's largest diving seabird, the emperor penguin Aptenodytes forsterii. Dive performance is also affected by stroke frequency in diving seabirds and in the fifth paper, Mori et al. (2010) consider optimization of this in South Georgian shags Phalacrocorax georgianus. This is followed by Shepard et al. (2010), who propose that swim performance is affected by depth-related buoyancy, which may modulate the pursuit speed of foraging imperial shags Phalacrocorax atriceps and thus constrain the size of prey taken. How efficiency relates to depth is also the subject of work by Zimmer et al. (2010) using data from emperor penguins, the deepest diving seabirds. The foraging behaviour of the deepest diving alcid, the thick-billed murre Uria lomvi, is documented by Ito et al. (2010), while Kokubun et al. (2010) consider the specifics of diving in this species with respect to the thermal structure of the ocean. The final contribution is by Shiomi et al. (2010), and highlights that artefacts in dive path reconstruction can occur if care is not exercised in dead-reckoning studies.

\section{LITERATURE CITED}

Boyd IL (1997) The behavioural and physiological ecology of diving. Trends Ecol Evol 12:213-217

Butler PJ, Jones DR (1997) Physiology of diving of birds and mammals. Physiol Rev 77:837-899

Elliott KH, Shoji A, Campbell KL, Gaston AJ (2010) Oxygen storage capacity and foraging behavior of two sympatric, planktivorous alcids. Aquat Biol 8:221-235

Ito M, Takahashi A, Kokubun N, Kitaysky AS, Watanuki Y (2010) Foraging behavior of incubating and chick-rearing thick-billed murres Uria lomvia. Aquat Biol 8:279-287

Kokubun N, Takahashi A, Ito M, Matsumoto K, Kitaysky AS, Watanuki Y (2010) Annual variation in the foraging behaviour of thick-billed murres in relation to upper-ocean thermal structure around St. George Island, Bering Sea. Aquat Biol 8:289-298

Kooyman GL (1989) Diverse divers. Springer-Verlag, Berlin

Lovvorn JR (2001) Upstroke thrust, drag effects, and strokeglide cycles in wing-propelled swimming by birds. Amer Zool 41:154-165

Lovvorn JR (2010) Modeling profitability for the smallest marine endotherms: auklets foraging within pelagic prey patches. Aquat Biol 8:203-219

Mori Y, Takahashi A, Trathan PN, Watanuki Y (2010) Optimal stroke frequency during diving activity in seabirds. Aquat Biol 8:247-257

Ponganis PJ, Meir JU, Williams CL (2010) Oxygen store depletion and the aerobic dive limit in emperor penguins. Aquat Biol 8:237-245

Shepard ELC, Wilson RP, Gómez Laich A, Quintana F (2010) Buoyed up and slowed down: speed limits for diving birds in shallow water. Aquat Biol 8:259-267

Shiomi K, Narazaki T, Sato K, Shimatani K, Arai N, Ponganis PJ, Miyazaki N (2010) Data-processing artefacts in threedimensional dive path reconstruction from geomagnetic and acceleration data. Aquat Biol 8:299-304

Wilson RP, Hustler PG, Ryan PG, Burger AE, Noldeke EC (1992) Diving birds in cold water: Do Archimedes and Boyle determine energetic costs? Am Nat 140:179-200

Wilson RP, Shepard ELC, Gómez Laich A, Frere E, Quintana F (2010) Pedalling downhill and freewheeling up; a penguin perspective on foraging. Aquat Biol 8:193-202

Zimmer I, Wilson RP, Beaulieu M, Ropert-Coudert Y, Kato A, Ancel A, Plötz J (2010) Dive efficiency versus depth in foraging emperor penguins. Aquat Biol 8:269-277 